\title{
EN BRAZOS DE LA MUJER MADURA... (Acercamiento a la tipología de la mujer madura en Francia, siglos XVII-XVIII: de la realidad a la ficción) ${ }^{1}$
}

DOLORES JIMÉNEZ

Universitat de València

Cuando Cándido, el héroe que da su nombre al cuento filosbfico de Voltaire, vuelve a encontrar a su amada Cunegonda tras tormentosas tribulaciones por esos mundos de Dios, elle ya no es la joven de 17 años, fresca, maciza y apetitosa. Aquella por la que Cándido mereció su expulsión del edénico castillo de Westfalia con una patada en el trasero se ha convertido en una mujer «triste, con ojos roncos, garganta seca, mejillas arrugadas, brazos enrojecidos y escamados», en suma todo lo que puede provocar la repulsa del personaje que no puede evitar sentirse sobrecogido de horror (así lo dice el cuento). Claro que el tiempo ha pasado, y no en vano para Cunegonda, aunque no sepamos cuanto con exactitud. Pese a todo, Cándido decide casarse con ella, y si bien él encuentra su salvación en una nueva filosofia de la vida (cultivar su jardín), ella, que supo antaño provocar la fogosa pasión de aquel joven ingenuo, se va desvaneciendo como personaje en una progresión bastante negativa hacia la vejez: «cada día se iba haciendo más fea, desabrida e insoportable» ${ }^{2}$ aunque la salva

' Conferencia pronunciada en el marco del curso impartido en la Universidad Menéndez Pelayo (Valencia) Climaterio: Cultura y Salud, Coordinación y Dirección: Fernando Bonilla, Felipe Garín, Elena Real, Alberto Romeu, Valencia, 2-5 de octubre de 1995.

3 Voltaire, Candide, Romans et contes, París, Gallimard, «Foliow, 1992, p. 231. Me permito traducir el texto yo misma, asi como todas las citas y referencias aqui presentadas. 
el talento de pastelera que va adquiriendo. Lo que pasa después, el texto no lo dice; ¿acaso sería atrevido afirmar que ya no hay lugar para el amor, sino el recuerdo que de él se tiene, una renuncia en suma al placer de los sentidos? La repulsión que siente Cándido por una Cunegonda envejecida, madura, tratada con clave de humor e ironía por Voltaire nos conduce a hacernos unas pocas preguntas: ¿a partir de qué momento una mujer, en los siglos XVII y XVIII cruza las fronteras de la madurez, se convierte en climatérica? ¿Cómo vive el amor? ¿Qué visión nos ha legado la literatura de entonces? A partir de algunos ejemplos, intentaremos formular algunas reflexiones que nos susciten este primer acercamiento a la problemática de la mujer en su edad más crítica quizás.

A primera vista, en el universo literario de aquellos siglos, el mundo pertenece a los muy jóvenes. Ellos y ellas son personajes muy guapos, ingenuos e inexpertos en las cosas del amor. El interés se centra en la iniciación amorosa, el descubrimiento de los sentimientos y de nuevas sensaciones. En la novela sentimental, las heroínas están asesoradas por madres, amigas viudas que intentan contrarrestar los efectos del enamoramiento y darles criterios éticos y morales de comportamiento. En la novela pornográfica que se desarrolla en la misma época, las heroínas son asesoradas por amigas mayores, antiguas cortesanas en general, que les dan una enseñanza teórica de la sexualidad que ellas después deberán poner necesariamente en práctica. En ambos casos, estas consejeras viven del recuerdo de sus experiencias pasadas que intentan transmitir. Forman parte del mundo de los adultos, de la familia y no siempre se precisa su edad. Poseen una sabiduría que las coloca en muchas ocasiones en un papel intermediario entre las dos generaciones. Su configuración como personaje es importante: ellas son las que inducen a las muy jóvenes a acatar las leyes morales de la sociedad (caso de la novela sentimental) o a transgredirlas (caso de la novela pornográfica), por este motivo tienen nombre, y estatus social. Por otra parte, también existen las viejas como tales: viejas anónimas - las llaman viejas-, no identificadas, que asumen el papel de guardianas de la virtud feminina; otras veces, son ecos difuminados del viejo tipo literario celestinesco.

En ese mundo de ficción al que remitimos, las vivencias del amor parecen ser una exclusiva de la juventud, algo efímero en suma, que sólo tiene un tiempo. De ahí que, cuando en las novelas se cuentan amores que perduran, se produzca cierta reacción de extrañeza entre el personal novelesco. Este es el caso de La Princesa de Clèves, gran novela clásica del siglo XVII, escrita por una mujer, Mme. de La Fayette, cuando tenía cuarenta y cuatro años. La jóven protagonista (sólo tiene 16 años) acaba de contraer matrimonio con el príncipe de Clèves, al que respeta profundamente sin amarlo. Poco después, en la corte del rey Enrique II (siglo XVI), se enamora apasionadamente del bello y seductor duque de Nemours, al tiempo que descubre los líos de la corte. Entre ellos, los 
amores del rey con la señora de Valentinois, la célebre Diane de Poitiers, que duran ya más de veinte años. La ingenuidad de la princesa frente a ese amor se plasma del modo siguiente en la novela:

La señora de Clèves, que tenía esa edad en la que uno no cree que una mujer pueda ser amada cuando ha pasado los veinticinco afios, consideraba con gran extrañeza el afecto que el rey tenía por esa duquesa, que era abuela, y que acababa de casar a su nieta. A menudo hablaba de ello con la señora de Chartres:

¿Es posible, señora, le decía, que haga tanto tiempo que el rey esté enamorado de ella? ¿Cómo ha podido unirse a una persona que era mayor que él, que había sido la amante de su padre, y que lo es de muchos otros, por lo que he oído decir? $?^{3}$

El punto de vista de la jóven princesa aquí citado presenta un interés especial por varias razones: en primer lugar, por considerar que una mujer, pasados los veinticinco años ya no es digna de amar y ser amada; queda implícito, en la opinión de la jóven, que es «vieja»; de lo que se deduce, en segundo lugar, una pregunta: ¿que debe hacer una mujer «vieja» o no tan joven?. Es más, la relación de un hombre con una mujer mayor que él parece chocar con la decencia de la época, aunque, como ya veremos, la práctica real y novelesca tienda cada vez más en ese sentido. Por fin, se plantea con este ejemplo literario, el tipo femenino de la cortesana, pero no de cualquier cortesana, sino la amante del rey, cuyo destino de favorita está generalmente ligado a la edad. ¿Acaso Mme. de La Fayette no recoge aquí un tópico de la época, que en cierto sentido sigue existiendo?

Vayamos por partes en el intento de cernir qué realidades sustentan este punto de vista expresado en la novela mencionada.

Si bien en la literatura, como decíamos anteriormente, aparecen prototipos de mujeres maduras, precisando o no su edad, podemos comprobar que se las presenta siempre desde un punto de vista moralizante, punto de vista alimentado por los discursos religioso y médico. Siempre tenemos dos tipos femeninos extremos (como en el caso de las jóvenes): la casta y la incontinente. Pero la realidad del envejecimiento nunca es expresado de modo explícito y siempre pasa por el tamiz de las conductas morales. Esa realidad habrá que ir a buscarla en los tratados médicos, aunque el discurso médico no se haya renovado en profundidad a lo largo de los siglos XVII y XVIII y se vayan arrastrando tópicos

${ }^{3}$ Madame de La Fayette, La Princesse de Clèves, Oeuvres Complètes, Preface de M. Déon, Texte établi, présenté et annoté par R. Duchêne, Editions François Bourin, 1990, pp. 286-287. 
hasta la saciedad, tópicos herededados de la Edad Media. En cambio, ya a finales del siglo XVIII, Tissot, médico suizo conocido sobre todo por su tratado sobre el onanismo (1760), en un Tratado sobre los nervios, intenta analizar, dentro de los fenómenos nerviosos que afectan a la mujer, cuáles son los síntomas de aquéllas que viven el cese de las reglas, época que sitúa alrededor de los cincuenta años, matizando después que a veces puede ocurrir a la edad de cuarenta y siete años o cuarenta y ocho años (con excepciones a los 36 años). Señala tambien que es una época considerada como muy peligrosa, pero, según él, el peligro no es tan grande, salvo que puede afectar a los nervios ${ }^{4}$. Aunque tributario todavía de una medicina bastante tradicional, Tissot intenta desmitificar ciertos tópicos como por ejemplo el del veneno de la mujer:

el nombre de edad crítica dado a esta edad, mete en el espíritu de todas aquellas que se acercan a el, un temor que, al ocuparlas continuamente, les provoca un mal real; $y$ de las que han muerto en ese momento, quizás más de la mitad, podemos decir al pie de la letra, han muerto de miedo.

Lo que había reforzado ese temor basado primero en algunos hechos, es la opinión quimérica según la cual la sangre menstrual es venenosa, y que retenida actúa como un veneno; esta opinión que no encontramos en los antiguos médicos griegos, pero que es un error que tenemos de los árabes que, al vivir en un pars muy caluroso, podían haber tenido algunos ejemplos de sangre menstrual estancada en la cavidad del útero, y habiendo amplificado esta idea, también se le ha añadido todo tipo de cuentos en manos de mujeres del pueblo; esta sangre es la misma que cualquier otra, el tiempo que se encuentra en las venas; aunque alli se estancase, no se pudre, y aunque se pudriese, no se corromperfa hasta el punto de hacerse venenosa. ${ }^{3}$

Al margen del discurso médico, pocos testimonios de mujeres nos cuentan cómo atraviesan la mencionada edad crítica. Acaso sea necesario rastraer la correspondencia privada de mujeres, célebres o no, donde al filo de la escritura se permiten hablar de su estado de salud. Un ejemplo interesante es el de Mme. de Sevigné, digna viuda perteneciente a la élite socio-cultural de la segunda mitad del siglo XVII, que ha dejado una correspondencia valiosísima, un testimonio de primera mano sobre la corte de Luis XIV y las costumbres del momento. En una carta que dirige a su primo Bussy-Rabutin, célebre por sus

4 Traité des nerfs et de leurs maladies par M. Tissot, t. III, Avignon, Chambeau, 1800, pp. 94-119.

Tissot, op. cit., pp. 103-104. 
escandalosos escritos como La historia amorosa de las Galas, en 1675, cuando ya tiene cuarenta y cuatro años, le confiesa brevemente:

He tenido muchos vapores, y esta buena salud, que visteis tan triunfante, ha recibido algunos ataques de los que me siento humillada, como si hubiese recibido una afrenta ${ }^{6}$

Un día después, le escribe a su hija y la informa de su salud: el médico «ha aprobado mi sangría del pie, y me ha impendido hasta ahora que me purgue, al considerar que ya estoy fuera de apuro y que ya no tendré esos vapores del año pasado. Era la despedida de lo que él cree que ya se ha marchado; tan poca cosa era digna de mi buen temperamento. Tendré que tomar sus polvos antes de marcharme, (...)" $)^{7}$.

Aquí tenemos con claridad formulado un aspecto de la patología femenina que los médicos observaban. Los célebres vapores eran el síntoma claro del paso de una frontera temporal llegando a provocar incluso la histeria -específica entonces de la mujer; tema muy discutido en el XVIII (por ejemplo por Diderot)- cuya causa profunda era, según los médicos seguidores de Galeno, la «retención y corrupción del semen o de los meses»". La retención del semen no era ni más ni menos que la ausencia de relaciones sexuales, de ahí que la histeria fuera considerada como la enfermedad por excelencia de la mujeres solas, viudas, abandonadas, religiosas o incluso aquellas que se casaban mayores.

Volviendo a Mme. de Sevigné, cuando ésta empezó a sentir serios trastornos físicos, y antes de conocer la causa real, recibió una carta de su primo quien, al enterarse de su estado de salud, le manifiesta, no sin algo de burla:

Me he enterado que habeis estado muy enferma, mi querida prima. Esto me ha preocupado por el porvenir y me ha obligado a consultar su mal a un médico de este país. Me ha dicho que las mujeres de buen temperamento como vos, que se han quedado viudas muy pronto, y que se habían contenido un poco, estaban sujetas a sufrir vapores. Esto me ha tranquilizado de la aprensión que tenía de que fuera un mal mayor; pues en fin, el remedio en vuestras manos, no pienso que odiéis lo suficiente la vida como para no usarlo, ni que tengais más

- Mme. de Sévigné, Correspondance. Texte établi, présenté et annoté par R. Duchêne, París, Gallimard, «La Pleíade», 1972 t. 2, carta del 6 agosto 1675, p. 32.

7 Mme. de Sévigné, op. cit., t. 2., carta del 7 de agosto de 1675, p. 40

- Citado por Yvonne Knibiehler/Catherine Fouquet, La femme et les médecins, Analyse historique, Hachette, 1983, p. 73. 
dificultades en tomar un galán que el vino emético. Deberíais seguir mi consejo, mi querida prima $(. . .)^{10}$

Los consejos socarrones de tomar un pretendiente, coinciden con las consideraciones de los médicos, y la referencia al «buen temperamento» de la marquesa alimenta el saber según el cual no es bueno que la mujer esté sola, aunque madura.

En el siglo anterior, el XVI, Brantôme, soldado y escritor que gustó de alabar a las mujeres de toda clase, conocido por sus diferentes Libros de las damas, en uno de sus textos Discurso sobre el amor de las Damas viejas y cómo algunas lo aman más que las jóvenes, recoge una sentencia que oyó en la Corte española en boca de una dama: «Que ningunas damas lindas o a lo menos pocas, se hacen viejas de la cinta hasta abaxom. El autor se aplica a demostrar, en cuanto a mujeres se refiere, que:

toda bella mujer que ha aprendido el juego del amor, no lo desaprende nunca, y seguir con ello le es siempre agradable y dulce; no es ni más ni menos que como cuando uno se acostumbra a una buena carne, cuesta mucho dejarla; y cuanto más va uno avanzando en edad, mejor es para la persona, es lo que dicen los médicos: además cuando mayor se hace una mujer, más golosa se hace de la buena carne a la que se ha acostumbrado; y si su boca de arriba le toma gusto, otro tanto le toma tambien su boca de abajo; y la golosina nunca se olvida, $\mathrm{ni}$ tampoco uno se cansa de ella con el peso de los años $(. . .)^{11}$

El ensalzamiento del sexo para la mujer madura viene ilustrado, en la pluma de este autor, por una serie de ejemplos ilustres y sabrosos de damas cuyo apetito sexual no disminuye con la edad, damas que siempre tienen galán dispuesto a consolarlas y más si tienen dinero.

Por otra parte, es en este autor en quien se inspiró Mme. de La Fayette en su novela para configurar el personaje de Mme. de Valentinois, amante del rey. Brantôme la toma como ejemplo de belleza eterna:

He visto a la señora duquesa de Valentinois, a la edad de setenta años, tan bella de rostro, tan fresca y también amable como a la edad de

- El emético era, al parecer, un polvo blanco cristalizado de oxycloruro de antimonio, potente vomitivo y buen purgante, puesto de moda por aquellos años del siglo XVII.

${ }^{10}$ Mme. de Sévigné, op. cit., t. 1, carta del 16 de agosto de 1674, p. 696.

"Brantóme, «Discours sur l'amour des Dames vieilles et comme aucunes l'ayment autant que les jeunes», Recueil des Dames, poésies et tombeaux, ed. établie, présentée par E. Vaucheret, París, Gallimard, «La Pléiade», 1991, p. 587. 
treinta años: por ello fue muy amada y servida por uno de los más grandes y valerosos reyes de este mundo ${ }^{12}$

Comenta además que la vio seis meses antes de morir:

su belleza, su gracia, esa majestad, su bella apariencia, eran iguales a las que siempre habra tenido. Y sobre todo era de una gran blancura, y sin maquillarse nada; pero dicen que todas las mañanas usaba algunas pócimas compuestas de oro potable y otras drogas que no conozco como los buenos médicos y sutiles apoticarios. Creo que si esta Dama hubiese vivido cien años, no hubiera envejecido, ni de rostro, por lo bien compuesto que lo tenía, ni de cuerpo, escondido y cubierto, por su buen temple y buena costumbre. iQué lastima que la tierra cubra esos bellos cuerpos! $!^{3}$

El retrato que este autor hace dista mucho de la primera vision que de este personaje hace la escritora Mme. de La Fayette, al inicio de la novela $\mathrm{La}$ Princesa de Clèves, cuando presenta la Corte:

los colores y los números de Mme. de Valentinois aparecían por todos los lugares, y ella misma aparecía con todos los ajustes de podra tener la señorita de La Marck su nieta, que era entonces casamentera ${ }^{14}$

En la misma novela, cuando la señora de Chartres le cuenta a su hija, la princesa de Clèves, la vida de la amante del rey, no ahorra los detalles que la configuran como una verdadera intrigante. Pero, prescindiendo del referente real, es posible que la autora no deje de estar condicionada por la mirada censora propia del circulo de amistades que frecuentaba: entre otros, Mme de Sevigne, cuyas cartas citábamos anteriormente, y La Rochefoucauld, noble y moralista autor de sentencias, con quien, dijeron las malas lenguas, Mme. de La Fayette mantuvo una profunda relación no tan casta como lo aparentaban. Ellos se reunfan en sus tertulias literarias para discurrir de casuística amorosa. En efecto, por aquellos años de la segunda mitad del siglo XVII, mientras la Corte orquestrada por el propio rey Louis XIV se entrega a los juegos más o menos inocentes del amor, éste sigue estando bajo sospecha, en todas las acepciones de la palabra, y con todas las realidades a las que remite. Se intentan

12 Brantôme, op. cit., pp. 604-605.

13 Brantome, op. cit., p. 605.

14 Mme. de La Fayette, op. cit., p. 269. 
codificar comportamientos amorosos cuando son incodificables. Pero, como bien dice un crítico actual, Philip Stewart, «entre la severidad de los discursos moralistas y la práctica, hay ciertamente un decalage $\rangle^{15}$. De modo que, a la mujer ya entrada en años, climatérica, se le respeta siempre y cuando ella respete las reglas de la decencia que mantiene la élite social aristocrática y la burguesía que ya se codea con ella. Otro caso es cuando, convertida en amante real, la mujer madura reta las leyes de la decencia por su estatus poderoso de favorita, y reta las leyes de la naturaleza intentando conservar su belleza, su aparente juventud para no perder su poder. Más allá de la intención moralizadora que Mme. de La Fayette da a la biografía de la duquesa de Valentinois en su novela - lección de cómo no se debe una conducir - se encuentra la lectura que la escritora podía hacer de la importancia de las favoritas reales en su época. En efecto, Luis XIV coleccionó sus amantes, de las que destacaron la duquesa de La Vallière, Mme. Montespan y Mme. de Maintenon con quien se casó secretamente, aunque a ésta última, con la edad, le dio por contaminar la Corte con su beatería. En el siglo XVIII, Luis XV, por su parte, tambien disfruto de los favores de Mme. de Pompadour y de Mme. du Barry. Pero el caso más interesante fue probablemente el de Mme. de Pompadour cuyo destino fue programado por su frívola madre. Educada desde muy joven para ser amante del rey, tuvo, por su inteligencia, su sabiduría y buen gusto, una poderosa y positiva influencia sobre el rey y sobre la cultura de la primera mitad del siglo XVIII. Cuando ya comenzó a sentir problemas físicos insalvables, y viendo que sus relaciones íntimas con el real amante se distanciaban, no dud6, con tal de no perder su poder, en delegar sus favores en jovencitas, que amigos del entorno del rey, -entre otros el viejo el duque de Richelieu-, le facilitaba siempre a cambio de interesantes compensaciones económicas ${ }^{16}$. Es evidente que estas bellezas de carne fresca y pulposa, eran de baja extracción, con lo que no resultaban ser serias rivales para la marquesa.

Al margen de estas amantes reales, no podemos obviar a la mujer que supo retar el tiempo con sus amores y que se convirtio en un verdadero mito, una leyenda que desbordó el propio siglo XVII: Ana de Lenclos más conocida como Ninon de Lenclos ${ }^{17}$. A esta mujer que muri6 a la edad de 85 años (en 1705), se le atribuyeron amantes hasta poco antes de su muerte. Fue, quizás por la

is Le masque et la parole. Le langage de l'amour au XVIII siècle, Paris, Jose Corti, 1973, p. 10.

16 Véase la biografia de Danielle Gallet, Madame de Pompadour ou le pouvoir féminin, Paris, Arthème Fayard, 1985, especialmente el capitulo VI «L'amour platonique».

17 Existen un sinfin de biografias más o menos noveladas de la sehoorita de Lenclos. La más reciente es un estudio de Roger Duchêne, Ninon de Lenclos, courtisane du Grand Siècle, París, Fayard, 1984. 
educación de su padre, una mujer libre y liberada que nunca quiso casarse, pese al difícil estatus que suponía entonces permanecer soltera. Trató con los espíritus más avanzados de su tiempo, libre pensadores como Saint-Evremond quien le dió el apodo de Leontium.

Después de haber seducido al marqués de Sévigné, esposo de Mme. de Sévigne, cuando llevaba tan solo seis de casado fiel, y otros famosos más, a la edad de 50 años seduce al hijo (en 1671). La madre comentará a su hija:

Pero, ¡qué peligrosa es esa Ninon! Si supierais cómo dogmatiza sobre la religión, os daría horror. Su celo para pervertir a los jóvenes es igual que el de cierto Señor de Saint-Germain ${ }^{18}$

En 1751, a raíz de la publicación de unas memorias sobre ella, Voltaire toma este pretexto para hacer, en una carta, una suscinta biografía de la dama a quien conoció poco antes de su muerte. Según el filosofo.

Su casa era hacia el final una especie de pequeño hotel de Rambouillet, donde se hablaba con mayor naturalidad, y donde habra un poco más de filosofía que en el otro. Las madres mandaban a su escuela a aquellos jovenes que querían entrar con agrado en el mundo. Se complacía en formarlos. ${ }^{19}$

Sin ser bella y tan solo agradable según dicen sus contemporáneos ${ }^{20}$, este Don Juan con faldas, no escapó a la maternidad. Tuvo un hijo de uno de sus amantes quien se ocupó de educarlo lejos de su madre. De la realidad a la ficción a veces siempre hay un paso. Le atribuyeron dos hijos del mismo amante, y se rumoreó que uno de ellos, a la edad de 19 años, le fue presentado y se enamoró locamente de ella. Ante su acoso, Ninon le tuvo que confesar que era su madre: el jóven se suicido. Este tema del incesto, tan presente en el imaginario dieciochesco, alimentó no pocas ficciones. Ninon se convierte en un tipo lite-

12 Este era un impio y depravado, amigo de un vecino de la marquesa, también impío y depravado, según la nota de Duchêne en su edición de las cartas de Mme. de Sévigné, Correspondance, op. cit, t. 1, p. 206.

19 Voltaire, *A Jean-Henri-Samuel Eomey», Correspondance, t. III (1749-1753), Paris, Gallimard, «La Pleiadew 1975, p. 400.

30 Tallemant dex Réaux, Ninon, Historiettes, t. II, París, Gallimard, «La Pléiade», 1961 p. 441: «Pues en cuanto a la belleza, nunca tuvo mucha; pero siempre tuvo mucho agrado». A. Adam, quien hace la edición crítica de este texto, cita en nota a Somaize: «En cuanto a la belleza, aunque sepamos que tiene la suficiente para provocar el amor, hay que confesar sin embargo que su espiritu era mas encantador que su rostro y que muchos escaparian a sus lanzas si se limitaran a verla." op. cit., p. 1281. 
rario. En la primera mitad del siglo, Lesage, en su novela Historia de Gil Blas de Santillana, historia de las andanzas de un pícaro en una España pasada por el tamiz francés, integra la historia de don Valerio de Luna.

Doña Inesilla de Cantarilla, dama vieja

era una persona prodigiosa. La naturaleza, -dice el texto-, le habia dado el singular privilegio de fascinar a los hombres en el transcurso de su vida, que duraba todavía después de quince lustros cumplidos. Había sido el ídolo de los señores de la vieja Corte, y se veía adorada por los de la nueva. El tiempo, que no perdona la belleza, se ejercia en vano sobre la suya; la marchitaba sin quitarle el poder de fascinar. Un aspecto noble, un espíritu encantador y gracias naturales le hacían arrancar pasiones hasta en su vejez. ${ }^{21}$

Don Álvaro de Luna, joven secretario del duque de Lerma, se enamora furiosamente de ella «con todo el furor que el amor y la juventud son capaces de inspirar» (p. 383). Tras perseguirla sin compasión, ella se ve obligada a revelarle que es su madre. Desesperación del jóven que se suicida. El final de la historia se presenta con una sugerencia nueva e interesante:

Se castigó como otro Edipo, con la diferencia que el Tebano se cego por arrepentirse de haber consumado el crimen, y que, por lo contrario, el castellano se atraves 6 de dolor por no haber podido cometerlo. ${ }^{22}$

Por otra parte, alrededor de 1750, Damours, un autor poco conocido del siglo de las luces, publica unas Cartas de Ninon de Lenclos, que más bien tienen apariencia de mistificación que de novela. En dicho libro, se presenta la supuesta correspondencia de Ninon con el marqués de Sevigné hijo, especie de educación sentimental de una dama a un joven: consejos sobre el amor, las mujeres, muy del gusto de la época. De seductora a consejera, el mito de Ninon planea sobre toda la primera mitad del siglo, pero siempre dirigido por una mirada masculina.

Es interesante observar de paso que en el siglo dieciocho, y siguiendo la tradición del siglo anterior, las mujeres son las que se especializan en novela sentimental, invocando a mujeres maduras que sirven para aconsejar jovencitas perdidas en sus sentimientos amorosos. En cambio, los hombres son los que practican la novela de galantería, libertina e incluso pornográfica, donde las

21 Lesage, Histoire de Gil Blas de Santillane, París, GF-Flammarion, 1977, Libro 8, p. 383.

22 Lesage, op. cit., p. 385. 
apreciadas mujeres maduras ya no tienen exactamente la misma función. $\mathrm{Si}$ bien en este caso pueden cumplir el rol de consejeras, tambien se convierten en iniciadoras de jovencitos a los juegos del amor. Este es el caso de una de las más apreciadas novelas de Crebillon fils, Los extravíos del corazón y la razón (1736-38), que pone en escena a un jóven de 17 años, Meilcour, y sus inicios en la vida social. De entrada, se encuentra con una amiga de su madre, la señora de Lursay, que le seduce y enseña las reglas del amor, aunque pronto se enamora de una jovencita. El interés central de la novela estriba en que el joven protagonista cuenta su historia desde la perspectiva de la experiencia que ha adquirido, y lo que siente con cada una de las mujeres: dos tipos de «amores», el del corazón y el de los sentidos, una de las claves temáticas de la novela de ese siglo. Sin embargo, la visión que nos da de la dama cuarentona no es muy complaciente en muchas ocasiones, si bien no puede evitar dejarse seducir por ella:

Al unirse a un hombre de mi edad, decidía la suya: pero para ella sólo era, sin duda, un ridículo más, y no era poca cosa un amante que, sobre todo, hasta ahora no había pertenecido a nadie. Todavía no era vieja pero notaba que iba a envejecer y para las mujeres en esa situación no se debe despreciar ninguna conquista.

Acaso hay algo más halagador para ellas que la ternura de un joven, cuyos arrebatos les devuelven sus primeros placeres, y justifican la estima que tienen todavia de sus encantos (...) Con un hombre ya formado, una mujer, (...), siempre tiene menos recursos: éste tiene más deseos que pasión, más coquetería que sentimiento, más delicadeza que naturalidad, demasiada experiencia para ser credulo, demasiadas ocasiones de disipación e inconstancia para sentirse única y fuertemente unido: hace, en un palabra, el amor con más decencia, pero ama menos. ${ }^{23}$

Esta larga cita extraída de la novela sugiere más de uno de los fantasmas masculinos de la época que se proyectan en la narrativa: la virginidad, el incesto velado, el intento de cernir la realidad del amor. Ahora bien, el prototipo de personaje que representa la señora de Lursay supone, pese a la mirada críti$\mathrm{ca}$, cierto reconocimiento de la mujer madura, experimentada, que decide vivir el amor desde un nuevo punto de vista. Ya no se trata de la mujer pasiva, de modo que bien se podría invertir la sentencia que la tía del seductor Valmont, en Las Amistades peligrosas, escribe a la presidenta Tourvel:

${ }^{23}$ Crébillon fils, Les égarements du coeur et de l'esprit, Romanciers du XVIIIème siècle, Préface par Etiemble, París, Gallimard, «La Pléiade», 1965, p. 28. 
El hombre goza de la felicidad que siente, y la mujer de la que proporciona. ${ }^{24}$

La novela Los extravios del corazón y la razón a la que hemos aludido puede ser, para la sociedad del XVIII, el síntoma de un cambio en la visión de la mujer, y en consecuencia, de la mujer madura. Sin embargo, no faltan voces filosóficas, como las de Diderot entre otros que, cuando sueña en torno al paraíso «natural» de Tahití, civilización primitiva descubierta por Bougainville, margina a las mujeres viejas porque ya no son fértiles: van cubiertas de un velo gris para ser reconocidas, y no pueden transgredir la ley bajo pena de castigo. Es evidente que la idea que se abría paso tambien era la de un amor más libre pero fundamentalmente orientado hacia la procreación. Ya se acercaba la revolución burguesa con sus consignas de patria, trabajo y familia.

Pese a todo, la novela galante y libertina, nos muestra mujeres como las Ninon, las señoras de Lursay, que, retando las leyes del tiempo como en un sueño eterno de juventud, con su experiencia, y ya menos «venenosas», se ven dotadas del derecho a gozar de la felicidad como los hombres. Ese derecho, más viable en la ficción que en otro lugar probablemente, sólo se podía contemplar entonces mediante la imagen narrativa del jóven que se entrega en los brazos de la mujer madura.

${ }^{24}$ Laclos, Les Liaisons dangereuses, Oeuvres Complètes, texte établi et présenté par Laurent Versini, París, Gallimard, «La Pléiaden 1979, carta CXXX, pp. 303-304. 